\title{
El espíritu humano y la dramaticidad de su transcendencia según el Monologion de San Anselmo ${ }^{1}$
}

\author{
Andrés Hubert \\ UNIVERSIDAD CATÓLICA DEL NORTE - ANTOFAGASTA \\ ahubert@ucn.cl
}

Resumen: El ser humano está inmerso en el mundo. La grandeza del hombre está en su deseo de conocer y su drama en que no puede asomarse fuera del mundo para estudiarlo completamente y en que su deseo permanece, sin embargo, ilimitado. Anselmo de Canterbury es un hombre de su tiempo que, sin embargo, interpela a los hombres de hoy. Su pensamiento comienza con el deseo de gozar del bien, deseo inscrito en cada hombre. Este trabajo intenta profundizar la cuestión de la relación entre el espíritu finito y el infinito en el Monologion de Anselmo. Comienza con el estudio de la palabra 'espiritu' y le descubre un profundo sentido relacional. Luego profundiza en las nociones 'imagen' y 'libertad' importantes para cualquier ser relacional, sea Dios o el hombre. Y termina con el sentido y la importancia de la fe como última y más profunda relación.

Palabras clave: Anselmo, Monologion, trascendencia, libertad, imagen, fe.

Abstact: Human being is immersed in the world. This is its greatness, it seeks to know the world and its drama: cannot move out of it to study it thoroughly. Anselm of Canterbury is a man of his time, nonetheless, meaningful today. His thought begins with the wish for good enkindled in every human being. This paper intends to deepen on the relation between the finite and the infinite spirit in Anselm's Monologion. Starts with the analysis of the word 'spirit' to discover a deep relational sense of the word. Then looks on 'image' and 'freedom', important to every relational being, God or man. And ends with the meaning and importance of faith as last and deepest relation.

Key words: Anselm, Monologion, transcendence, liberty, image, faith.

1 Este trabajo se inscribe en un trabajo colectivo dentro del FONDECYT regular 1130019 (2013-2014): El espíritu finito y su dramaticidad en el mundo. Un estudio histórico sistemático en Edith Stein, Anselmo, Juan de la Cruz y Karl Rahner. 
Los avances de la ciencia de hoy han ayudado a la teología a profundizar su relación con estas mismas ciencias y el sentido de la presencia de Dios dentro del mundo creado. ¿Puede lo Infinito unirse con lo finito? ¿Puede lo finito expresar con exactitud lo infinito? O hablando como teólogo, ¿puede ser válida una teología actual si no presenta una teología de la naturaleza? ¿Puede ser válida una teología de cualquier época si no presenta directa o indirectamente una visión de Dios desde la naturaleza? Más aún, ¿̇i no presenta, aunque sea de manera inconsciente, un estudio sobre Dios desde la naturaleza, desde la creación y no solamente desde el ser humano? "Los cielos cuentan la gloria de Dios", reza el Salmo $\left(\right.$ Sal 19, 1) ${ }^{2}$. Cuando hablo de naturaleza, quiero hablar de las ciencias naturales (o ciencias exactas), y no de la teología natural que presenta a un dios relojero o un dios con un diseño inteligente. Para los cristianos, "la doctrina de la Trinidad sigue expresando la intuición de que, bajo la superficie de todas las cosas, se desarrolla sin receso un inconmensurable drama en el que se hallan involucradas las diversas funciones de las tres personas trinitarias, un misterio de amor y creatividad al que es incorporado para siempre todo lo que transpira en el universo finito" 3 .

Los cristianos hablamos de 'imagen'. Con eso, afirmamos que, bajo este misterio insondable que llamamos 'Trinidad', existe algo que nos permite entrar en él. Dios nos ha creado a su imagen (Gn 1, 27-28). Además, lo invisible de Dios se puede entrever a través de su creación $(\mathrm{Rm} 1,20)$. Si hay imagen, esto significa que algo refleja a la Trinidad, aunque sea a través de un espejo o en enigma (1 Co 13, 12). Significa también que la Trinidad se puede conocer de alguna manera. Anselmo dirá más: la creatura fue hecha para conocer a la Trinidad a través de lo que es ella misma. Esto es el drama que queremos estudiar.

En la época de Anselmo de Canterbury (siglos XI-XII), la ciencia estaba muy lejos de alcanzar el desarrollo que tiene hoy. Además, Anselmo es metafísico y teólogo, es monje y arzobispo. Tiene muy pocos estudios científicos según su época y, al parecer, no le interesa mucho cualquier estudio sobre la materia. Su finalidad es vivir su fe y mostrar que esta

2 Caeli enarrant gloriam Dei. Las citas bíblicas de este trabajo son traducciones desde la edición de la Vulgata que era la edición que conocía Anselmo.

3 Haught J. F. Cristianismo y ciencia. Hacia una teología de la naturaleza (Santander, Sal Terrae 2009) 98. 
ayuda a todo ser humano a vivir plenamente feliz. Anselmo pone en marcha los criterios de la razón: en el Monologion trabaja 'sola ratione' y en el Cur Deus Homo anuncia que avanza 'remoto Christo'. Para Anselmo, todo lo que la razón concibe es real. Así hace entrar a Europa en la experiencia de la razón ${ }^{4}$. Pero, ¿ayuda Anselmo a encontrar a Dios desde o bajo la realidad de las cosas materiales?

En este trabajo quiero estudiar principalmente el Monologion de Anselmo5. Partiremos de la palabra 'Spíritus' para ver su significado tanto en Dios (que es Espíritu o Espíritu Santo) como en el hombre. Veremos que hay una relación entre Dios y su creación, relación que no es solamente intelectual, sino real. Entonces (segunda parte) tendremos que estudiar al hombre como imagen y como ser libre. Veremos, por fin, que el drama del espíritu finito se vive en la realización plena de su vida como espíritu libre y como imagen de Dios, como ser libre que tiene una imagen impresa en el fondo de su naturaleza.

\section{PRIMERA PARTE: EL ESPÍRITU}

La palabra 'Spiritus' se utiliza por primera vez en el Monologion en el capítulo 27. Anselmo busca profundizar una descripción de la Naturaleza Eminente: habla de simplicidad (cc. 15-17); es sin principio ni fin (c. 18). Contiene todo y no es contenida (cc. 19-24). Ningún accidente la puede cambiar (c. 25). Puede declarar entonces que es sustancia (c. 26) a condición de recalcar que esta sustancia está por encima de toda sustancia. Por eso, hay que aclarar lo que es esta sustancia porque la $\mathrm{Na}$ -

4 Cantin A., "S. Anselme au départ de l'aventure européenne de la raison”, en: FoREVILle R., (Ed.), Les mutations socio-culturelles au tournant des XIe et XIIe siècles (Paris, éd. du CNRS 1984) 611-622.

5 Para las obras de Anselmo, se utiliza la edición crítica de F.s. Scmitt, S. Anselmi Opera Omnia (Stuttgart, Fr. Frommann Verlag 1968-1984) (2 vols.). Las traducciones son personales con la ayuda de la edición francesa de M. Corbin: L'oeuvre de S. Anselme de Cantorbéry (Paris, Cerf, 1986ss) (7 vols. editados que se citará como: Corbin I, II, etc,). Las abreviaciones para los libros de Anselmo son: CDH (Cur Deus Homo), CONC (De Concordancia), DCD (De Casu Diaboli), Dla (De Libertate Arbitrii), DV (De veritate), EP (Epistola), MED (Meditación), MON (Monologion), PR (Proslogion). La manera de citar es la siguiente: capítulo; página, línea o líneas. A veces, se citará solamente la página (p.) o la línea (L.). Las citas sin indicación del libro refieren siempre al MON. Las abreviaciones de los libros de la Biblia se conforman a las habituales según la Biblia de Jerusalén. 
turaleza eminente existe de por sí e hizo todo de la nada ${ }^{6}$. Es decir, hay una separación infinita entre la Naturaleza eminente que es sustancia eminente y las demás sustancias. Además esta sustancia es única. Por eso, toda apelación llama a una explicación.

Se habla de sustancia (c. 27) como universal (ser humano es común a todos los humanos) o individual (todos los hombres tienen en común con otros, el ser humanos). Para la Naturaleza eminente se puede nombrarla por lo más digno. En cuanto sustancia, lo más digno es el espíritu y el cuerpo, y de ambos, el más digno es el espíritu.

Anselmo no define la palabra 'espíritu', como tampoco la palabra 'Naturaleza', es decir, la supone conocida por sus lectores. A nosotros, que no vivimos en su tiempo, nos gustaría conocer mejor su vocabulario. Por el momento, aceptemos que, para Anselmo, lo más digno es lo real, lo concreto (a diferencia de lo noético, lo pensado) y entre lo real, el espíritu es más digno que el cuerpo ${ }^{7}$. Anselmo no dice razones; lo da por supuesto. No se trata de un dualismo (alma-cuerpo) aunque puede estar subyacente. Sabemos desde ya que no es cuerpo (es 'espiritual'), que la Naturaleza eminente es espíritu y que este espíritu no es mutable ni divisible: es absolutamente espíritu individual ${ }^{8}$.

El c. 28 profundiza: este espíritu es singular y es el único que existe: lo demás no es. Este espíritu es simple, es decir, es (ni fue ni será). Por derecho se dice que es simplemente, absolutamente y perfectamente $(28 ; 46,9)$. Las demás cosas apenas son ${ }^{9}$. Además son porque están sostenidas. Así este espíritu es por derecho de cierta manera el único ser (L. 26). Por eso, Anselmo lo llama "Espíritu creador" (L. 30). Las demás creaturas fueron hechas algo desde la nada (L. 31).

Una vuelta atrás nos ayudará. Para Anselmo, la palabra 'nada' es importante. Ya en el c. 6, Anselmo estudia el 'per nihil - ex nihilo': nada es per, ex nibilo. Esto le permite decir que todo lo que existe, existe por algo y este algo es anterior, pero la Esencia eminente no es anterior a sí misma $(6 ; 19,18.29)$. Entonces no es su propia materia para existir (p. 20, 12). Resuelve el dilema con el ejemplo de la luz: "la luz luce o es luciente por

26; 44, 12-13: Per se est quidquid est et de nihilo facit omne aliud esse.

7 Cf. PR 6; 104, 25: spiritus, qui corpore melior est (El espíritu que es mejor que el cuerpo).

$8 \quad$ 27; 45, 19: omnino individuus spiritus.

$9 \quad$ Vix est (p. 46, 14); vix esse (L. 16). 
sí misma o de sí misma"10 (p. 20, 14). Quizás un moderno no aceptaría este ejemplo porque, desde nuestra mentalidad científica, sabemos que la luz proviene de algún origen (el sol, un motor). Anselmo ciertamente medita a Jn 1, 5: La luz luce en las tinieblas ${ }^{11}$. En el c. 8, Anselmo explica tres maneras de entender la nada. Aparta inmediatamente las dos primeras y se extiende en la tercera: "se dice que algo fue hecho de nada cuando entendemos que fue realmente hecha, pero no existe algo desde lo cual fue hecho" como cuando alguien está triste sin causa (sine causa $^{12}(8 ; 23,18-20)$. Anselmo seguirá profundizando la relación entre la nada y el algo, entre la semejanza y la desemejanza que existe entre la Naturaleza eminente y la naturaleza creada (cc. 9ss).

Con el c. 29, Anselmo empieza a hablar de una diversidad en el Espíritu único. Considera las propiedades de la Naturaleza eminente: Esta naturaleza eminente crea por su palabra (locutio). Esta locución es el mismo Espíritu eminente (L. 9). Ahora sabemos que "solo subsiste el Espíritu creador y su creatura"13 $(29 ; 47,13-14)$. Es evidente que la locución de este Espíritu no es creatura porque todo fue hecho por ella ${ }^{14}$ (L. 15). Y si no es creatura, solo puede ser el Espíritu Eminente.

Por la locución, el Espíritu eminente dice y reconoce todas las cosas. Entonces esta locución es la inteligencia de este Espíritu. Hay consustancialidad entre el Espíritu eminente y su locución. Además, esta locución es simple: es una sola palabra (verbum) (c. 30). Y (c. 31) no se asemeja a las cosas creadas porque estas difieren en grado de esencia y dignidad.

Aquí hay una dificultad: todo verbo, porque dice una cosa, debe asemejarse a la cosa (c. 32). Pero este verbo del cual hablamos, no depende de las creaturas. El verbo es verbo del Espíritu eminente y debe existir porque sin este verbo, el Espíritu eminente no podría decir ni entender nada, ni siquiera a sí mismo.

Ya el espíritu racional se acuerda de sí mismo y se entiende y así puede distinguirse de las creaturas irracionales u otras creaturas (c. 33). Entonces el Espíritu eminente se acuerda de sí y se entiende como lo hace

\footnotetext{
Lux lucet vel lucens est per seipsam et ex ipsa.

Lux in tenebris lucet. Cf. Jn 8, 12: Ego sum lux mundi.

12 Dicitur aliquid esse factum de nihilo, est cum intelligimus esse quidem factum, sed non esse aliquid unde sit factum... contristatus sine causa.

13 Nihil potest subsistere praeter crentem spiritum et eius creaturam.

14 Cf. Jn 1, 3.
} 
todo espíritu racional, o mejor, el espíritu racional actúa a semejanza del Espíritu eminente. Así el Verbo es co-eterno.

Hay un solo Verbo, repite el c. 34, para decirse a sí mismo y para decir a las creaturas. Verbo va con intelligere que es leer (legere) dentro (intus), es decir, leer interiormente ${ }^{15}$. Además, como el Verbo es eterno, cuando el Espíritu eminente se dice, al mismo tiempo dice las cosas creadas, porque todas están en él de alguna manera, como el arte en el artista. Y entonces (c. 35), como es lo mismo para el Espíritu eminente saber y entender, vemos que sabe todo y entiende todo cuando lo dice. Y la ciencia del Espíritu eminente es infinitamente superior a la ciencia humana (c. 36). Por eso, lo creado es distinto en sí mismo que en nuestro conocimiento. En conclusión, todo lo que hace el Espíritu eminente, su Verbo lo hace de manera semejante (c. 37). Y todo lo que es el Espíritu eminente con respecto a las creaturas, así también su Verbo.

Profundicemos (c. 38) para entender mejor el Espíritu eminente y su Verbo. Cada uno es verdad eminente y es creador, y no hay dos verdades ni dos creadores. Hay una unidad y una pluralidad, pero no de la misma manera como existe en la creación (cuando se habla de dos líneas o de dos hombres). En este sentido, no son dos espíritus iguales, o dos creadores iguales. Tampoco son dos verbos o dos imágenes. Es decir, "no se puede expresar lo que los dos son como Espíritu eminente y su Verbo, aunque por algunas propiedades de cada uno, por obligación son dos"16 $(38 ; 56,28-30)$.

El Verbo nace de la Esencia eminente (c. 39). Esto significa que no es del Espíritu eminente de la misma manera que la creación. Es creador del creador ${ }^{17}$, es decir, el mismo del mismo. En resumen, es del Espíritu eminente al nacer. No como el cabello que nace de la cabeza, sino, como

15 Gilbert P., "Prouver Dieu et espérer en Lui”, Nouvelle Revue Théologique (1996) 707. Garcia de Lomas Mier j., El 'Intellectus Fidei' en San Anselmo de Canterbury, (Pamplona 1994, https:// hdl.handle.net/10171/9512 [15 de mayo 2013]) 147. ForTuny F. J. Anselmo de Canterbury, pensador de la modernidad (www.ub.es/telemac [23 de abril 2013]) 40: lee inter-legere, es decir leer entre dos teorías mientras que com-prehendere es tomar en conjunto.

16 Exprimi non potest, quid duo sint summus Spiritus et Verbum eius, quamvis quibusdam singulorum proprietatibus cogantur esse duo.

17 39; 57, 7: creator de creatore. La preposición "de" con ablativo, indica la procedencia de la cosa que queda unida con su origen. La preposición "ex" indica la procedencia con separación. 
un hijo que nace de sus padres. Así el Verbo existe y nace desde el Espíritu eminente ${ }^{18}$.

Por eso, la mejor manera es hablar de Padre e Hijo (c. 40) para expresar la semejanza: así el Verbo del Espíritu eminente es de la Esencia de este. El Espíritu eminente engendra y el Verbo es engendrado (c. 41). En cuanto a los apelativos (c. 42), Anselmo prefiere 'Padre' (y no 'Madre') por ser el padre la causa principal de la paternidad, e 'Hijo' por ser más parecido al padre.

El Padre (genitor) y el Hijo (engendrado) tienen que ser distintos y, al mismo tiempo, deben ser lo mismo (c. 43). Es decir, la esencia de cada uno es la misma (quod est). El Padre es perfectamente Espíritu eminente y el Hijo igualmente, pero no son dos Espíritus, sino uno solo, aunque el Padre en su singularidad y el Hijo en su singularidad sean un Espíritu perfecto. Son opuestos en sus relaciones y concordes por su naturaleza, de tal manera que cada uno tenga la esencia del otro.

Así se insiste en la unidad y simplicidad de la Naturaleza eminente (c. 44). Pero es mejor decir que el Padre es esencia del Hijo que lo contrario (c. 45) porque el Hijo tiene su esencia del Padre. Pero no olvidemos que cada uno tiene la esencia del otro. Así el Hijo es poder y sabiduría o verdad del Padre y también justicia y todo lo que conviene a la Esencia del Espíritu eminente.

El Hijo es sabiduría, ciencia: conoce, sabe y saborea (cc. 46-47). Está claro que el Verbo nace de la memoria (c. 48): así ocurre en nuestra mente, porque "pensar una cosa de cuya memoria tenemos, es decirla por la mente" 19 (48; 63, 20-21). Así el Hijo nacido del Espíritu eminente es Hijo de su memoria ${ }^{20}$. El Hijo es memoria nacida de la memoria.

Ahora si hablamos de comunión, tenemos que contemplar el mutuo amor (c. 49). "El Espíritu eminente se ama así como se recuerda y se entiende" 21 (49; 64, 18-19). De la misma manera, la mente racional une amor con memoria e inteligencia.

39; 57, 12.18: ex illo. Cf. Nota anterior.

19 Rem etenim cogitare cuius memoriam habemus, hoc est mente eam dicere.

20 48; 64, 2: proles est memoriae eius.

21 Summus Spiritus se amare, sicut sui menor est et se intelligit. Cf. L. 23-24: Amat ergo seipsum summus Spiritus, sicut sui memor et se intelligit. 
Es evidente que el amor es consecuencia lógica de la memoria y de la inteligencia (c. 50). Así "el amor del Espíritu eminente procede el Él (ex eo) porque se acuerda de sí y se entiende" $22(50 ; 65,8)$. Si en la memoria del Espíritu eminente vemos el Padre, en la inteligencia el Hijo, entonces el amor del Espíritu eminente procede de igual manera del Padre y del Hijo. En consecuencia (c. 51), si el Espíritu eminente se ama, el Padre ama al Hijo y recíprocamente. Cada uno por separado es Espíritu eminente y ambos juntos son un solo Espíritu eminente. Entonces es necesario que se amen de un solo amor.

Entonces viene la pregunta (c. 52): ¿el amor es tan grande como el mismo Espíritu eminente? El amor es igual al Espíritu eminente y esto significa que el Amor es Espíritu eminente (c. 53) y como no puede haber varias Esencias eminentes, entonces el Padre, el Hijo y el Amor mutuo son una sola Esencia eminente. "El mismo amor es entonces Sabiduría eminente, Verdad eminente, Bien eminente y todo lo que se puede decir acerca de la sustancia del Espíritu eminente"23 $(53 ; 66,11-13)$.

El amor procede de la esencia del Padre y del Hijo, y no de la pluralidad (c. 54). Es decir, el Padre es Espíritu eminente e igualmente el Hijo y no hay dos Espíritus eminentes. Entonces "el Amor del Espíritu eminente emana entero del Padre en su singularidad y entero del Hijo en su singularidad, y no son dos enteros que manan juntos del Padre y del Hijo, sino uno solo idéntico que mana entero"24 (54; 66, 27-29).

Este Amor es igual al Padre y al Hijo (c. 55), pero no es Hijo. No es ni engendrador ni engendrado (c. 56). Tampoco es inengendrado porque sale del Espíritu eminente ${ }^{25}$. Cada cual, el Padre, el Hijo y el Amor, es increado y creador (c. 57). Sin embargo, hay un solo increado y creador. El amor procede por 'espiración'. Por eso, "el Amor de la Esencia eminente puede ser llamado convenientemente su Espíritu”26 (57; 69, 2). Pero como el Padre y el Hijo no son Espíritu de alguien, se puede estimar el Amor como "Espíritu de ambos porque procede de ambos

22 Amorem summi Spiritus ex eo procedere, quia sui memor est et se intelligit.

23 Est igitur ídem amor summa sapientia, summa veritas, summum bonum, et quidquid de summi Spiritus substantia dici potest.

24 Ita a singulo Padre manat totus amor summi Spiritus, et singulo Filio totus, et simul a Padre et Filio non duo toti, sed unus idemque totus.

25 56: 68, 1: A summo Spiritus exiens.

26 Eiusdem amor satis convenienter appellari potest Spiritus eius. 
cuando espiran admirablemente de modo indecible"27 (L. 5-6). Es comunión del Padre y del Hijo, y por eso, puede asumir como propio el nombre común del Padre y del Hijo: a título propio se le llama 'Espíritu', lo que es la sustancia del Padre y del Hijo. Entonces el Espíritu es esencia, sabiduría o potencia del Padre y del Hijo por el hecho que tiene lo mismo que ellos (c. 58).

"Es agradable contemplar (c. 59) cómo el Padre, el Hijo y el Espíritu de ambos son mutuamente uno en el otro con una igualdad tan grande que ninguno supera al otro" 28 (59; 70, 3-4). Cada uno está totalmente en los demás porque cada uno es perfectamente la Esencia eminente: cada uno es memoria, inteligencia y amor. El Padre es memoria, el Hijo es inteligencia y el Espíritu amor y ninguno necesita de los demás porque cada uno por separado es Esencia eminente y Sabiduría eminente (c. 60). Pero si cada uno es memoria, inteligencia y amor (c. 61), esto produce confusión. Ya se vio que el Padre no es Hijo ni Espíritu de otro; todo lo que es, lo es engendrando y haciendo proceder. Así también el Hijo es lo que es siendo engendrado y haciendo proceder. El Espíritu es lo que es procediendo.

Además (c. 62), cada uno, el Padre, el Hijo y el Espíritu, se dice y dice a los demás. Al parecer, hay numerosos verbos. Los seres humanos decimos nuestros pensamientos con muchas palabras. Pero en nosotros, el verbo de la cosa pensada no nace de la cosa misma, sino de una cierta semejanza. En la Esencia eminente, el Padre, el Hijo y su Espíritu son siempre presentes a sí mismos. Es mejor decir (c. 63) que, aunque los tres existen, no son varios los que son dichos. Para el Espíritu eminente, decir es ver como si pensara ${ }^{29}$ y así pasa en nosotros. Sabemos que todo lo que pertenece a la esencia de la Naturaleza eminente conviene al Padre, al Hijo y a su Espíritu, cada uno en su singularidad. Y aunque se diga de los tres, no hay pluralidad. Así cada uno tiene ciencia e inteligencia sin que sean tres los que dicen. Además, aunque cada uno, es decir, el Padre, el Hijo y el Espíritu de ambos, se diga, el verbo es único, pero no se le llama Verbo de los tres, sino de uno solo. El Hijo es único y no

27 Iste autem aestimatur Spiritus utriusque, quia ab utroque suo quodam inenarrabili modo spirante mirabiliter procedit.

28 Iucundum est intueri in Patre et Filio et utriusque Spiritu, quomodo sint in se invicem aequalitate, ut nullus alium excedat.

29 63; 73, 10-11: Nihil autem aliud est summo Spiritui huiusmodi dicere quam quasi cogitando intueri. 
puede ser imagen o hijo de sí mismo o del Espíritu que de él procede. No imita el Espíritu ni existe a su semejanza, porque no es por él ( $a b$ illo), sino que es Espíritu por este ( $a b$ isto). Entonces hay un solo Padre, un solo Hijo y un solo Espíritu que procede: ninguno es otro y cada uno es perfecto y no necesita de otro.

Desde el c. 64 del Monologion, Anselmo describe la fe: aunque todo sea incomprensible, hay que investigar si se conserva la certeza de la fe. La incomprensibilidad no va contra la fe. Es importante quedarse en la solidez de la certeza ${ }^{30}$. Todo el camino recorrido ayudó a "comprender racionalmente que es incomprensible" 31 (64; 75, 11).

Todo lo visto es inefable (c. 65) porque la Naturaleza eminente está eminentemente por encima de nuestra naturaleza. Las palabras que utilizamos son enigma, hablamos a través de un espejo (1 Co 13, 12), es decir, hablamos a través de otro (per aliud). Para conocer a la Naturaleza eminente (c. 66), hay que acercarse a ella a través de una semejanza: la mente racional es el mejor espejo (c. 67) porque se recuerda, se entiende y se ama. El esfuerzo de la creatura racional (c. 68) es expresar esta imagen impresa en ella. A través del discernimiento, se da cuenta que fue hecha para amar a la Naturaleza eminente. Así vivirá feliz (c. 69).

Además, el amor tendrá su retribución (c. 70): gozar eternamente de la Naturaleza eminente, mientras el desprecio llevará a la miseria eterna (c. 71). Esto prueba que el alma es inmortal (c. 72) y vivirá feliz o infeliz (c. 73). El alma debe tender siempre hacia el Bien eminente (c. 74) y tener esperanza (c. 75). Amar y esperar significan creer (c. 76). La fe no es solo tender hacia ella (ad illam), sino llegar a ella (in illam).

Esta fe va en relación con el Padre, el Hijo y su Espíritu, a cada uno y a los tres juntos (c. 77). Es la única Esencia en la cual (in quam) debemos creer. Creer significa perderse en ella (in illam). La certeza de la que hablábamos se une a la fe y al amor (dilectio) (c. 78). La fe vive por las obras, por la caridad (Gal 5, 6). Entonces la fe viva (St 2, 20) es la que cree en eso en que debe creer (in id in quod) y la fe muerta es la que cree solamente eso que debe creer $(i d \text { quod })^{32}$.

\footnotetext{
30 64; 75, 4: fidei certitudinem. L. 10: certitudinis soliditas.

31 Rationabiliter comprehendit incomprehensibile esse.

32 78; 85, 8-9: viva fides credere in id in quod credi debet, mortua vero fides credere tantum id quod credi debet.
} 
El hombre debe creer (c. 79) en (in + ac.) una cierta e inefable unidad trina y trinidad una. Unidad por la Esencia, trinidad por las personas, Padre, hijo y Espíritu de ambos. Estos nombres -Padre, Hijo y Espíritu de ambos- son los más convenientes. Indican una Esencia o Naturaleza y tres personas o sustancias. "Persona se dice solamente de la naturaleza racional individual y sustancia de las naturalezas individuales que se mantienen sobre todo en la pluralidad"33 $(79 ; 86,7-8)$. Los accidentes van con la sustancia, lo que no tiene la Esencia eminente.

Esta Esencia eminente es Dios (c. 80), él es el Espíritu eminentemente bueno y eminentemente potente. Es el único "de quien, por quien y en quien son todas las cosas" ${ }^{34}(80 ; 87,6-7)$. Es el único Dios inefablemente trino y uno.

El recorrido ha sido extenso. El De Libertate Arbitrii (dla) nos ayuda. Recuerda que la realidad del ser humano (la naturaleza racional), por no guardar la rectitud, se hace esclavo del pecado y así se transforma en un "espíritu que se va y no vuelve" ${ }^{35}$. Anselmo cita textualmente la Vulgata. El Salmo 78 recuerda las bondades de Dios que contiene su furor ante los numerosos pecados porque se acuerda que el hombre es carne, es decir, débil, un soplo que va y no vuelve $(\mathrm{Sal} 78,39)^{36}$. El hombre vive del soplo de Dios y este podría retirar su soplo (Sal 104, 29-30). Si Dios no retira (o no retira todavía) su soplo es por pura misericordia. Pero sabemos que "no permanecerá para siempre su soplo en el hombre porque es carne $^{37}(\mathrm{Gn} 6,3)$. El hombre es carne: esa es su debilidad y la causa de la misericordia de Dios. Generalmente se traduce 'spiritus' por soplo tanto en la traducción de Anselmo como en la de la Biblia. Nuestra hipótesis es que, aquí, debemos traducir por 'espíritu'.

Anselmo no retiene el 'quia caro est' y une el texto del Salmo con la esclavitud del pecado (Jn 8, 31) ${ }^{38}$. Para la creación del hombre, la Vulgata indica que Dios "inspiró en su cara un soplo de vida” (Gn 2, 7) y

33 Persona non dicitur nisi de individua rationali natura, et substantia principaliter dicitur de individuis quae maxime in plurlitate consistunt. Cf. c. 27.

34 Ex quo et per quem et in quo sunt omnia. Cf. Rm 11, 36; 1 Co 8, 6.

35 DLA 10, 222, 9-10: spiritus vadens et non rediens.

36 Recordatus est quia caro sunt, spiritus vadens et non rediens.

37 Non permannebit spiritus meus in homine in aeternum quia caro est.

38 DLA 10, 222, 9-10; sic ergo fit spiritus vadens et non rediens, quoniam qui facit peccatum, servus est peccati. 
utiliza la palabra 'spiraculum'39. Es posible ver entonces que 'spiritus' sea más que un soplo. Si el espíritu (como hemos visto) es la individualidad y/o la esencia, se puede traducir el texto de Anselmo como "el hombre se transformó en un individuo que va y no vuelve porque el que hace el pecado es esclavo del pecado". El pecado es esclavitud. El espíritu va y no vuelve porque, como esclavo, no puede volver a su estado original. Y, proclama Anselmo, es un milagro más grande devolver la rectitud a quien la perdió (y entonces es esclavo del pecado) que devolver la vida a un muerte ${ }^{40}$. Esto significa que, para Anselmo, el 'espíritu que va y no vuelve' es el hombre en cuanto pecador, sujeto a la pura misericordia de Dios. La palabra 'spiritus' indica entonces al ser humano en su realidad actual y/o original, es decir, su esencia, así como 'Spiritus' es la esencia del Dios Trinidad.

Concluyamos esta primera parte. El estudio de la palabra 'Spiritus' nos ha llevado por varios caminos. Hemos visto que Anselmo no define la palabra 'Spiritus' que usa para definir tanto la Naturaleza eminente como el Espíritu Santo y el ser humano. Hemos visto que Anselmo afirma que el espíritu es mejor que el cuerpo. ¿Hay en eso un dualismo platónico? Es posible. Acotemos sin embargo que, cuando Anselmo define su proyecto, indica que todos los bienes se buscan "a través de los sentidos corporales que experimentan y a través de la razón que discierne" 41 (1; 14, 6-7). Anselmo decidió tomar el camino de la sola razón (sola ratione). ¿Esto significa que la experiencia sensible no es necesaria o es defectuosa? Parece que no. Anselmo insistirá en la importancia de la experiencia para la fe.

En el c. 5 del Monologion, Anselmo utiliza la imagen del artesano (artifex) para explicar las preposiciones 'ex' y 'de. Después, desechará esta imagen del artesano (faber) en c.11 para superarla: si hay semejanza entre la Substancia creadora y el obrero, también hay una gran desemejanza. $(11 ; 26,6-7)$. El obrero necesita materia prima y conocimiento previo para trabajar (L. 16). La Substancia creadora es causa prima y las cosas creadas existen solo por ella. Lo que hace el obrero tiene que existir

39 Et inspiravit in faciem eius spiraculum vitae.

40 DLA 10; 222, 13-14: Et maius miraculum existimo cum Deus voluntati desertam reddit rectitudinem, quam cum mortuo vitam reddit amissam (estimo cuando Dios devuelve a la voluntad la rectitud perdida, es un milagro mayor que cuando devuelve a un muero la vida perdida).

41 Et sensibus corporeis experimur et ratione mentis discernimus. 
antes para que él lo pueda reproducir (L. 20-23). Lo importante con el uso de las preposiciones, es mostrar que no se trata solamente de una causa. Por eso hemos hablado de 'sin causa'. Lo que importa para Anselmo es establecer una relación. No se trata de una relación causal. Se trata de una relación como la que existe entre las personas. Y solo el ser humano puede reconocer y decir la relación ${ }^{42}$. Por eso después, Anselmo hablará de la Trinidad en término de relación (cc. 43 y 54).

Si hablamos de relaciones entre personas, el Monologion tiene otro sabor y las palabras tienen otra profundidad, especialmente nuestra palabra 'espíritu'. Dios es inmutable mientras el ser humano progresa hacia Dios. El 'hace' todo y no pierde su inmutabilidad. Hablar de crear o hacer de la nada es otra manera de expresarla inmutabilidad. Podemos ver ahora que Dios hace, pero no como el artesano (artifex. c. 5) o el obrero (faber: c. 11). El 'artifex'hace arte, el 'faber'fabrica, y Anselmo rechaza el ejemplo. Para Dios, 'hacer' es dar nombre a todo de tal manera que salga fortalecido el hombre interior por el Espíritu. Así en Cristo, podemos comprender la totalidad de la caridad sobre-eminente de la ciencia de Cristo para llenarse en toda la plenitud de Dios (Ef 3, 14-20). El 'hacer' de Dios es entonces el comienzo de la promesa; es un intercambio de regalos $^{43}$ donde Dios se regala y pide a la creatura su entrega total. Estamos en la Alianza. Estamos en relación.

Así se entiende que Anselmo insista en que el ser humano fue creado para ver el rostro de $\operatorname{Dios}^{44}$, en que la creatura racional fue hecha para amar $(68 ; 79,1-5)$. Ver el rostro, amar, esto significa relacionarse. No se trata de ontología o de ética. Dios nos amó primero y eso funda la revelación escatológica $(70 ; 80,24 s s)$. El hacer desde Dios debe ser acompañado de un deber de la creatura: "Porque me hiciste, me debo entero a tu amor, me debo a tu amor más que yo mismo, por cuanto eres más grande que yo. Debo más que yo mismo entero. Todo lo que soy es tuyo por creación, hazlo entero tuyo por afecto" ${ }^{45}$.

42 MON 15 tiene 1 empleo de 'relatio', 4 de 'relative' y 4 de 'relativus'.

43 Corbin M., La Pâque de Dieu (Paris, Cerf 1997) 305. Lo que sigue se debe en parte al final del libro del P. Corbin.

44 Cf. PR 1.

45 MED III, 192-193.194-195.197-198.200: Quia me fecisti, debeo amori tuo me ipsum totum [ ...] Debeo amori tuo plus quam meipsum, quantum tu es maior me [...] Plus debeo quam me ipsum totum [...] Totum quod sum tuum est conditione; fac totum tuum dilectione. 
Toda creatura existe porque fue hecha por gracia, anuncia Anselmo ${ }^{46}$. La unión de hacer y gracia muestra que la creación no es pura fabricación. La gracia describe el sentido de la relación. La creatura racional es la única capaz de esta gracia porque recoge el gemido de toda la creación $^{47}$.

Tenemos que profundizar más la relación. "La Substancia eminente dijo de alguna manera (quasi) en ella a toda creatura antes de crearla según la misma y a través de su misma locución interna" ${ }^{48}(11 ; 26,3-5)$.

En primer lugar, estamos ante un 'decir'. Dios dice la creación. Esto refleja el sentido bíblico de la creación donde Dios habla para crear (Gn 1), donde "la Palabra estaba cerca de Dios y la Palabra era Dios. Estaba en el principio cerca de Dios. Por ella todo fue hecho" ${ }^{49}$ (Jn1, 1-3). Sabemos también que Dios "dice y todo se hace, manda y todo es creado" 50 $($ Sal 33, 9). Dios no solo dice, sino que "llama a los que no son así como los que son" ${ }^{51}$ (Rm 4, 17).

Además si la Substancia eminente es simple, el mundo, la creación, no puede ser un accidente (mon 25). La relación no la cambia. Anselmo toma el ejemplo de un hombre que va a nacer. Su nacimiento y su vida no cambiarán nada de mi substancia, tenga o no relaciones con él. Es decir, las cosas creadas no mueven la inmutabilidad de Dios.

La relación está dada gratuitamente; no depende de la creatura. Por eso, tenemos que reconocer que "solo existe realmente el Espíritu creador. Las cosas creadas no son. Pero no son totalmente inexistentes, porque fueron hechas algo de la nada por él que es el único que es de manera absoluta" $52(28 ; 46,30-31)$ y "toda naturaleza creada se mantiene

46 CONC III,2; 264, 18: Omnis enim creatura existit, quia gratia facta est.

47 Corbin M., La Pâque... 310. Cf. Rm 8, 20 ss.

48 Summam substantia prius in se quasi dixisse cunctam creaturam, quam eam secundum eandem et per eandem suam intimam locutionem conderet. Alli se inserta el ejemplo del faber, visto supra.

49 Et Verbum erat apud Deum, et Deus erat Verbum. Hoc erat in principio apud Deum. Omnia per ipsum facta sunt.

50 Ipse dixit et facta sunt; mandavit et creata sunt. Cf. Ez 36, 36; Ez 37, 14.

51 Vocat ea quae non sunt, tanquam ea quae sunt. Cf. Is 48, 13: ego vocabo eos, et stabunt simul.

52 Solus ille creator Spiritus est, et omnia creata non sunt; nec tamen omnino non sunt, quia per illum, qui solus absolute est, de nihilo facta sunt. 
en un grado más alto de esencia y dignidad según se acerque a él"53 (31; 50, 12-13). Es importante, entonces entender que Anselmo no es esencialista. Siempre está el amor subyacente. El intellectus fidei es más que un sistema, es un camino por recorrer ${ }^{54}$.

SEGUNDA PARTE: LA IMAGEN - LA LIBERTAD

El estudio del vocablo 'espíritu' nos conectó con el Espíritu eminente que es primero; todo lo demás es creación y, por lo tanto solo existe porque él lo quiere, porque él llama y entabla una relación con sus creaturas. Tenemos que preguntarnos ahora cuál es la relación exacta entre la Naturaleza eminente y la naturaleza creada, cómo definirla. Por eso, tenemos que hablar en primer lugar de la imagen y de su relación con la libertad.

\section{La Imagen}

La imagen es algo sensible. El órgano de la vista permite ver lo sensible; la memoria visual nos permite imaginar las figuras sensibles $(10 ; 25$, $7 \mathrm{ss})$. Démonos cuenta inmediatamente de la diferencia entre el cuerpo (sensible) y la razón (no sensible): el cuerpo nos muestra una imagen o figura sensible; la razón piensa la esencia universal. La vista me muestra tal hombre; la razón me dice 'animal racional mortal' (L. 7-9) ${ }^{55}$.

Hay en eso una aproximación al conocimiento: “Todas las palabras que empleamos son semejanzas o imágenes de las cosas de las cuales son palabras" $\$ 6$ (31; 48, 19-20) y toda imagen se parece más o menos a la realidad. Esto significa que ninguna palabra nuestra corresponde exactamente a lo que es la realidad. Hay entonces una ambigüedad en el conocimiento, pero, añade Anselmo, esta ambigüedad no puede seguir:

53 Omnem creatam naturam eo altiori gradu essentiae dignitatisque consistere, quo magis illi propinquare.

54 Corbin M., La Pâque... 323 y 326.

55 Per corporis quidem imaginem, ut cum eius sensibilem figuram imaginatur; per rationem vero, ut cum eius universalem essentiam, quae est 'animal rationale mortale' cogitat (la mente humana piensa por la imagen del cuerpo, como cuando imagina su figura sensible, pero piensa por la razón como cuando imagina la esencia universal, que es 'animal racional mortal').

56 Similitudines et imagines sunt rerum quarum verba sunt. 
"La verdad del hombre está en el hombre vivo; en la pintura, tenemos la semejanza o imagen de esta verdad" 57 (31; 49, 2-3).

La solución es reconocer la verdad del existir en el verbo cuya esencia es eminente $(31 ; 49,4)$ porque toda esencia fue hecha por él y según él (L. 5) y él es el verbo de la Verdad eminente (L. 6). También para ella misma, "la mente racional cuando piensa en sí misma, entiende que nace una imagen en su pensamiento, aún más, que este pensamiento de sí es su imagen formada para su semejanza, así como desde una impresión suya" 58 (33; 52, 13-15). Si tomamos el ejemplo de un hombre ausente, cuando pienso en él, mi pensamiento se forma a su imagen, $y$ esta imagen me viene a la mente por la memoria (L. 22), "y esta imagen es el verbo del mismo hombre"59 (L. 23). La imagen es entonces "el pensamiento de sí formado para su semejanza como desde su impresión, aunque la mente no pueda separarse de su imagen, excepto por la razón" ${ }^{60}$ (L. 25-27). Esta imagen es su verbo (L. 27). Es decir: hablamos de consubstancialidad y alteridad del pensamiento y de su verbo. Así la Sabiduría eminente, cuando se dice, engendra para sí una semejanza consubstancial (p. 53, 1). Este verbo es "semejanza, imagen, figura, carácter"61 (L. 4).

El Espíritu eminente y su Verbo son dos, pero no son dos verdades ni dos creadores (c. 38), ni dos imágenes $(38 ; 56,24)$. El Verbo es imagen para con el otro, porque es imagen de alguien (L. 25). De allí se ve la dificultad de expresar la dualidad del Espíritu eminente. Por eso, Anselmo busca expresar la realidad con la idea del Hijo engendrado (cc. 39ss).

En cuanto al Amor, no puede ser Hijo aunque sea semejante (c. 55). El Verbo es Hijo porque "manifiesta una imagen patente del Padre" 62 $(55 ; 67,7)$ mientras que "el Amor no exhibe una semejanza tan trans-

57 In vivo homine veritas hominis esse dicitur, in picto vero similitudo sive imago illius veritatis.

58 Cum mens rationalis seipsam cogitando intelligit, imaginem ipsius nasci in sua cogitatione; immo ipsam cogitationem sui esse suam imaginem ad eius similitudinem tamquam ex eius impressione formatam.

59 Quae imago verbum est eiusdem hominis.

60 Cogitationem sui ad suam similitudinem quasi sua impressione formatam; quamvis ipsa se a sua imagine non nisi ratione sola se parare possit.

61 Similitudo ita et imago et figura et caracter eius.

62 Promptam praeferendo parentis imaginem. 
parente de Aquel del cual es semejanza"63 (L. 9). Por eso, Anselmo habla de 'proceder'.

En el ser humano que piensa algo, el verbo nace de una cierta imagen o semejanza porque esta cosa está fuera (absens) de su mente. En la Esencia eminente, el Padre, Hijo y Espíritu Santo, cada uno está totalmente presente (praesens) al otro $(62 ; 72,16 \mathrm{ss})$. Uno solo es imagen verdadera $(63 ; 74,3)$, es imagen e hijo de Aquel del cual es el verbo (L. 9-10), pero no es imagen de sí mismo ni del Espíritu que de él procede (L. 10).

Nosotros hablamos por enigmas, "vemos algo no con propiedad, tal como es la cosa, sino a través de cierta semejanza o imagen, como cuando miramos el rostros de alguien en un espejo" 64 (65; 76, 14-16). La mente racional cuando se estudia a sí misma, alcanza cierto conocimiento de la Esencia eminente (c. 66). Por eso, "la mente racional es para sí como el espejo, en el cual se refleja la imagen de esta Esencia que no puede ver cara a cara" ${ }^{65}(67 ; 77,27-28)$. Es imagen porque puede recordar, reconocer y amar a la Esencia eminente (p. 78, 3.5) que es la más grande y la mejor. Solo en la mente racional fue inscrita (inditus) en su esencia la imagen del Creador (L. 11). Esto es el punto de partida desde donde Anselmo invita a todo ser humano a crecer y "expresar por su voluntad esta imagen impresa en su naturaleza" $66(68 ; 78,15-16)$.

La relación que habíamos descubierto anteriormente hablando del espíritu, se nos profundiza ahora. Se trata de recoger plenamente nuestra naturaleza que es racional y libremente, expresarla totalmente. Hay una dificultad que tenemos que visualizar: se nos habla de una imagen interior, natural (inditus, impressus) y de una voluntad que expresa (expressus) ¿Cómo unir ambas realidades? ¿Cómo hablar de libertad?

Pero antes, resumamos. Anselmo une siempre imagen con semejanza cuando habla del ser humano. Es evidente que está meditando el libro del Génesis: "Hagamos al hombre para nuestra imagen y semejanza

63 Tam perspicuam exhibet eius ex quo est similitudinem.

64 Vidimus aliquid non proprie, quemadmodum res ipsa, sed per aliquam similitudinem aut imaginem; ut cum vultum alicuius consideramus in speculo.

65 Ipsa sibimet esse velut 'speculum' dici potest, in quo speculetur imaginem eius, quam 'facie ad faciem' videre nequit.

66 Hanc imaginem sibi per naturalem potentiam impressam per voluntarium effectum exprimere. 
[...]. Y Dios creó al hombre para su imagen" ${ }^{67}$ (Gn 1, 26-27). También en estos textos, recuerda a Pablo: "el hombre es imagen y gloria de Dios"68 (1 Co 11, 7); "Ahora vemos en un espejo en enigma, entonces veremos cara a cara" ${ }^{9}$ (1 Co 13, 12).

\section{La Libertad}

En el Monologion, Anselmo habla poco de la libertad y la presenta solo como una ausencia de trabas: "Si alguien vive libre de todo mal, entonces vive feliz"70 $(69 ; 80,2)$ y la libertad del cuerpo celestial será la falta de obstáculo como cuerpo espiritual' ${ }^{71}$. En su libro 'De Libertate Arbitrii' (DLA), Anselmo define la libertad de elección como "el poder de conservar la rectitud de voluntad para esta misma rectitud"72. La rectitud es querer lo que Dios quiere que yo quiera ${ }^{73}$. La libertad es, entonces, hacer lo que se debe y no lo que se quiere.

En el siglo $\mathrm{XI}^{74}$, los monasterios eran un oasis de paz en medio del caos reinante. Ellos están al origen de los estudios (eclesiásticos, teológicos, literarios), de la economía originada en el cultivo de la tierra, de la reforma de la Iglesia con la teología de los sacramentos, de la reforma de las costumbres (los sínodos o concilios regionales), de la reforma gregoriana tanto en la liturgia como en el nombramiento de los obispos. Todo esto muestra que nace una civilización nueva. La Iglesia instaura la 'paz de Dios' para mitigar y frenar el clima de violencia.

El ser humano depende de su dueño, sea el Señor local o el Rey en el plano civil, sea el obispo o el Papa en el aspecto religioso. La obediencia es fundamental. La estructura civil y religiosa refleja la voluntad de Dios

${ }^{67}$ Faciamus hominem ad imaginem et similitudinem nostram... Et creavit Deus hominem ad imaginem suam.

68 Vir imago et gloria Dei est.

69 Videmus nunc per speculum in aenigmate: tunc autem facie ad faciem.

70 Si quis autem ab iis liber vivit, beate vivit.

71 PR 25; 118, 21: libertas corporis cui nihil obsistere possit. Después cita a 1 Co 15, 44.

72 DLA 3; 212, 20: Potestas servandi rectitudinem voluntatis propter ipsam rectitudinem.

73 DLA 8; 221, 3: Velle, quod Deus vult illum velle.

74 Para lo siguiente: Castañeda F., “CCómo pensar la libertad a finales del S XI? El caso de Anselmo de Canterbury”, en: VV. AA., Identidad doble - Doppelte Identität. Schriften der Johannes Gutenberg-Universität, Heft 11, Mainz (1998) 21-37. 
al que es obligatorio escuchar. Obedecer (oboedire) significa escuchar (audire). Anselmo se inscribe en este mundo y lo revoluciona.

El De Casu Diaboli (dcd) continuará la misma idea: conservar la justicia es querer lo que se debe y abandonarla es querer lo que no se debe $e^{75}$. Acotamos aquí que, para Anselmo, hay un sentido profundo, monástico de la obediencia y, al mismo tiempo, hay un querer, es decir un acto personal de la voluntad y este acto individual se une a un deber. Deber significa aceptar acoger lo que Dios da. Cuando pedimos a Dios que perdone nuestras deudas, le pedimos que nos ayude a acoger plenamente los dones recibidos: pedimos la plenitud de la comunión con Él y con todos los hombres. El pecado es querer lo que no debe, así como Eva que quiso ser semejante a Dios antes que Dios lo quiso. Así se alejó de la justicia. Es decir, quiso más de lo que debía: quiso lo que Dios no quería que quisiera, quiso ser semejante a Dios de manera desordenada.

Nada ni nadie puede asemejarse a Dios ${ }^{76}$. La existencia de Dios y la excelencia de Dios (es decir, que nadie le sea semejante) son obvias. El solo hecho de querer algo (aunque sea algo menos que Dios) sin la orden de Dios es querer algo "con voluntad propia por encima de la voluntad de Dios"77, no sometido a nadie (L. 9). El pecado del demonio, y todo pecado, es poner la voluntad propia por encima de la voluntad de Dios. Así el demonio se hizo semejante o superior de Dios; no quiso recibir la perseverancia.

Entonces la libertad es querer lo que Dios quiere. La libertad es la posibilidad, a través y más allá de lo finito, de tomar una posición para con Dios ${ }^{78}$. Ella depende de la existencia de Dios. Por eso el Monologion y el Proslogion definen cada uno a su manera esta existencia. No existe una prueba de la existencia de Dios. Solamente hay una definición de esta existencia que, para Anselmo, es obvia.

75 DCD 4; 241, 1-2: Iustitiam vero nullus servat nisi volendo quod debet. Neque deserit nisi volendo quod non debet. Lo que sigue es estudio de este c. 4.

76 DCD 4; 241, 31-32: Si Deus non potest cogitari nisi ita solus, ut nihil illi simile cogitari possit... (si Dios no puede ser pensado sino como único, de tal modo que no pueda ser pensado nada que le sea semejante). Está presente el argumento del Proslogion. Para Anselmo, la existencia de Dios no es problemática; sí lo es la existencia del pecado (Corbin II, 371, nota 21).

77 DCD 4; 242, 10: voluntam suam supra Dei voluntatem posuit.

78 DEME D., "The 'origin' of evil according to Anselm of Canterbury", Heythrop Journal 43 (2002), 171 y nota 6, 182. 
La libertad es obedecer a Dios porque es reproducir su imagen y, al mismo tiempo, es totalmente personal porque nadie abandona la rectitud contra su voluntad. Un hombre puede ser amarrado contra su voluntad, puede ser torturado, ser asesinado contra su voluntad, pero "no puede querer contra su voluntad porque no puede querer, no queriendo querer. Todo hombre que quiere, quiere su propio querer"79. Nadie abandona la rectitud si no es voluntariamente. Ni siquiera Dios la puede quitar. Para Anselmo, cada ser humano tiene voluntad propia. En un mundo donde todo pertenece a otro, donde la voluntad del Señor o de la Iglesia reina en absoluto, Anselmo afirma que nadie puede erigirse como soberano de otra voluntad. Allí nace el concepto moderno de individualidad $^{80}$. Quizás Anselmo esté meditando nuevamente la carta a los Gálatas (Gal 4, 6-7). El hijo no es esclavo, es hijo y heredero; el hijo no paga impuesto (Mt 17, 24-27). La esclavitud nace con el pecado (Jn 8,34 , citado varias veces en dla).

Para profundizar, recordemos las definiciones anselmianas. "La verdad es la rectitud perceptible a la sola mente" "1.; "la justicia es la rectitud de voluntad conservada por ella misma" 82 y "la libertad de elección es el poder de conservar la rectitud de voluntad por esta misma voluntad" $\$ 3$.

El De Libertate Arbitrii advierte que la libertad no es escoger entre lo bueno y lo malo. Esta es la trampa en la cual es muy fácil caer ${ }^{84}$. El hombre fue creado para gozar de lo bueno o del Bien ${ }^{85}$; "fue hecho para verte" ${ }^{86}$. Entonces la libertad es la búsqueda de cómo vivir cada vez más

79 DLA 5; 214, 21-23: velle autem non potest invitus quia velle non potest nolens velle. Nam omnis volens ipsum suum velle vult. Invitus tiene 30 empleos en este solo capítulo; y 4 empleos en el resto del DLA.

80 Castañeda F., Cómo... 35.

81 DV 11; 191, 19-20: Veritas est rectitudo mente sola perceptibilis.

82 DV 12; 194, 26: Iustitia igitur est rectitudo voluntatis propter se servata.

83 DLA 3; 212, 19-20: Libertas arbitrii est potestas servandi rectitudinem voluntatis propter ipsan rectitudinem.

84 DLA 8; Corbin M., "Introduction au DLA", en Corbin II, pp. 183-184.

85 Es tema fundamental del Monologion en una inclusión: 1; 8, 7; 14, 5ss y 80; 87, 6-7. Además, el Proslogión habla del "único necesario en el cual todo es bien, o mejor, que es todo bien, el bien entero y único (PR 23; 117, 20-22: Porro hoc est illud unum necessarium, in quo est omne bonum, immo quod est omne et unum et totum et solum bonum).

86 PR 1; 98, 14-15: Ad te videndum factus sum, et nondum feci propter quod factus sum. El argumento del Proslogion es relacional antes que ontológico. 
plenamente esta finalidad. Este discernimiento une elección y amor. Lo racional no es solamente lo intelectual o abstracto; es también lo amoroso. Esto supone lo concreto y la manera de enfocar lo concreto de cada día. Como en el Monologion, lo escatológico está presente: fue hecho para alcanzar algún día lo que ama y elige ${ }^{87}$.

Lo importante para nosotros es que el recibir indica que hay una relación y qué tipo de relación. El pecado es un contrasentido ${ }^{88}$. Dios se define 'per se' (Mon 6 y 15) y la creatura 'per aliud'. Dios es per se, pero para definirlo, hay que referirse al mundo ${ }^{89}$, sin olvidar que Dios es más grande que el mundo. El pecado es revertir la creación y pensar que la creatura puede vivir y actuar per se.

La justicia no es solo algo recibido, es una relación con el Dios mayor. Por eso, no se puede entender el 'debere' como una obligación moral, sino como una deuda que nace en la creación misma. Esta deuda, porque es relación, marca la relación con Dios e indica el propio crecimiento de la creatura ${ }^{90}$. La relación significa correspondencia de la voluntad humana a la voluntad de Dios: eso es el 'debere'. Es relación con el Dios siempre mayor. Dios es porque es ${ }^{91}$.

Veamos eso a través de lo imposible en Dios. Ya el Proslogion estudiaba lo imposible en Dios (pr 7). El De Libertate Arbitrii (dla) lleva este estudio hasta lo extraordinario: "Dios puede reducir a nada toda substancia que hizo de la nada, pero no es capaz (non valet) de apartar esta rectitud de la voluntad que la tiene" ${ }^{\prime 2}$. Esta es la afirmación inaudita y extraña. La rectitud es la imagen de la rectitud divina. La rectitud es querer lo que Dios quiere que quiera, es decir, es ser como Dios: hay en eso todo un sentido escatológico. Por eso, el que pierde la rectitud es

87 Anselmo empezará el segundo libro del $\mathrm{CDH}$ con un resumen del MON. Es admirable que las palabras más notables son: 'Assequi' (II, 1; 97, 19.21.22) y 'amare et eligere' (II, 1 ; 97, 10.11.15.18.19-20.20-21.21.22).

Corbin M., "Introduction..., ", en CORBIN II, 193. Cf. el estudio de la nada en DCD 11.

Corbin II, 195. Cf. Pr 2 y Jn 14, 28.

90 Corbin II, 371, nota 16. Corbin M., "De l'impossible en Dieu. Lecture du 8ème chapitre du dialogue de Saint Anselme sur la liberté”, Revue des Sciences Philosophiques et Théologiques (1982) 531.

91 DV 10; 190, 4: nec ulla ratione est quod est, nisi quia est.

92 DLA 8; 220, 13-15: Totam quidem substantiam quam de nihilo fecit, potest redigere in nihilum, a voluntate vero habente rectitudinem non valet illam separare. Cf. Jn 10, 28-29; 6, 37-38; Rm 8, 38-39. 
esclavo del pecado porque no puede recuperarla por sí mismo. Dios que la dio una primera vez, es el único que puede devolverla otra vez. Por eso, es un milagro más grande que devolver la vida a un muerto. Dios no puede quitar la rectitud de quien la tiene porque, si Dios quiere hacerlo, entonces no quiere que el hombre quiera lo que Él quiere que quiera: llegamos a una contradicción porque lo que Dios quiere es conservar la justicia (dv 12). Llegamos a algo imposible para Dios ${ }^{93}$.

¿Cómo ver esta imposibilidad? Dios no puede dejar de ser Dios; no puede dejar de ser Padre de Cristo desde la eternidad, es decir, no puede separar al hombre de la rectitud ${ }^{94}$. La relación con Dios es una unión más allá de la creación y más fuerte que la creación. La última palabra sobre el hombre no es que sea creatura, sino que es hijo en el Hijo ${ }^{95}$. Esta unión llega en lo más profundo de Dios: a una consubstancialidad en el Hijo.

Entonces, ¿por qué una imposibilidad? Volvamos al Proslogion. En el c. 7, Anselmo se refiere a cosas imposibles de encontrar en Dios: no puede corromperse, no puede mentir, no puede hacer que lo verdadero sea falso, no puede hacer que lo que existe no haya existido, etc. ${ }^{96}$. Sin embargo, todo lo que parece limitación en Dios, lo hace más grande porque Dios no puede nada por impotencia y nada ni nadie puede contra él97. Así se entiende el poder misericordioso de Dios (Pr 8-11). Así también describe Pablo el poder y la sabiduría de Dios frente a la locura humana (1 Co 1, 23ss). Dios es fiel. Se entiende entonces que pecar es dudar de Dios y de su fidelidad en Cristo. Tan importante es este tema para Anselmo que volverá a purificarlo años después al final del Cur Deus Homo: "La misericordia de Dios que parecía perecer cuando considerábamos la justicia de Dios y el pecado del hombre, la encontramos tan grande y tan acorde a la justicia que ni mayor ni más justa se puede pensar" ${ }^{98}$. En

\footnotetext{
Corbin M. "De l'impossible...” 537.

Corbin M. "De l'impossible..." 540.

Corbin M. “De l'impossible...” 541.

PR 7; 105, 9ss.

PR 7; 106, 1.
}

98 CDH II, 20; 131, 27-29: Misericordia vero Dei quae tibi perire videbatur, cum iustitiam Dei et peccatum hominis considerabamus, tam magnam tamque concordem iustitiae invenimus, ut nec maior nec iustior cogitari possit. Cf. Rm 11, 32; Tt 3, 4-7. 
Cristo, su Hijo, Dios nos ha mostrado su misericordia, la relación más justa que puede existir.

En resumen, digamos que el estudio de la imagen y de la libertad nos permitió profundizar el tema de la relación que habíamos desarrollado en la primera parte. Podemos ahora en una tercera parte, dedicarnos a la transcendencia y a su drama.

TERCERA PARTE: EL DRAMA DE LA TRANSCENDENCIA

En la primera parte estudiamos el lenguaje y llegamos a la importancia de la relación. En la segunda, desde dentro y fuera del Monologion, profundizamos la antropología de Anselmo y nuevamente la relación del hombre con Dios. Tenemos que ver ahora el drama de la transcendencia: el hombre es un ser finito, creado que desea poseer el Bien que es el mismo Creador.

Anselmo empieza su Monologion (Mon 1-4) partiendo de las cosas visibles, sensibles, obvias, para llegar rápidamente a la Esencia eminente que es lo único que existe realmente. Descubre y describe esta Esencia eminente y, desde ella, reproduce todo lo que existe. La Naturaleza eminente es Trinidad y es el Bien máximo deseado. El ser humano (como toda creatura y más que otras creaturas) se recibe de la Naturaleza eminente y solo el ser humano es imagen porque recuerda, entiende y ama. Hemos insistido en la relación que existe entre la Naturaleza eminente y la naturaleza humana.

Finalidad y $\mathrm{Fe}$

En su esfuerzo por explicar la búsqueda del Bien, Anselmo insiste en la finalidad escatológica de la creación. El c. 67 del Monologion recuerda que la creatura racional es imagen del Creador porque tiene el poder de recordar, entender y amar. E inmediatamente, Anselmo presenta la finalidad de esta creatura (c. 68). La creatura racional debe expresar voluntariamente la potencia natural impresa en ella. Debe a su Creador lo que es (recordar, entender y amar) y ahora debe querer todo esto. Su voluntad se pone en marcha y este querer es lo mejor ${ }^{99}$. La razón permite discernir ${ }^{100}$ y debe amar lo que discierne ser bueno. La finalidad es entonces

99 Melior: 68; 78, 20 - Magis: L. 20.

100 Cf. c. 1; 14, 7: ratione mentis discernimus. 
amar o rechazar. Es decir: "existe para esto (ad hoc): amar a la Esencia eminente por encima de todo bien porque ella es el Bien eminente"101 $(68 ; 79,2-3)$. Y debe usar todo su poder y su querer para eso, porque para eso (ad quod) reconoce su propio ser que tiene este poder y querer.

El c. 69 empieza con una declaración: "no hay duda que el alma humana es la creatura racional" $102(69 ; 79,12)$. Entonces Anselmo se dedica a expresar y explicar su finalidad ${ }^{103}$. La finalidad es amar (L. 13), amar sin fin (L. 14) o perder este amor (L. 15). Pero sería impío decir que fue hecha para despreciar; entonces fue hecha para amar sin fin. Para esto, debe vivir para siempre (L. 19) y libre de todos los males (p. 80, 2). "Está claro que el alma humana es tal que si conserva su finalidad (id ad quod est) vivirá feliz y totalmente libre de la misma muerte y de toda otra molestia" ${ }^{104}$ (L. 4-6).

El c. 70 habla de la retribución: "el Justo y Poderoso retribuye al que lo ama con perseverancia" $105(70 ; 80,9-10)$. ¿Es pelagianismo? Parece que no. El ser humano recibió el poder de amar y usa este poder (L. 11). Lo importante es la perseverancia en el amor (L. 14). Démonos cuenta también que Anselmo, en su manera de pensar, no hace diferencia entre alma racional, creatura racional y ser humano. En adelante, también seguirá hablando de alma o de creatura. Recordemos que el espíritu es más digno que el cuerpo. Lo importante es que la creatura racional no era nada y recibió una esencia racional (L. 15). La recompensa será el mismo Bien eminente. Ahora lo vemos en espejo o imagen (p. 81, 1). Lo disfrutará sin fin.

El c. 71 muestra las consecuencias del desprecio del amor. Hay castigo porque no usó para sí "hacia eso hacia lo cual fue hecha"106 $(71 ; 81$, 12). Es lógico que, si desprecia amar, padecerá la miseria eterna que es la indigencia inconsolable (p. 82, 3). Si el ser humano fue creado para bus-

101 Rationalem creaturam ad hoc esse factam, ut summam essentiam amet super omnia bona, sicut ipsa est summum bonum. Cf. p. 78, 25-26

102 Dubium autem non est humanam animam esse rationalem creaturam.

103 Ad hoc: 69; 79, 13.14.15.16.18 - ad quod: L. 20.

104 Liquet igitur humanam animam huiusmodi esse, ut si servet id ad quod est, aliquando vere secura ab ipsa morte et omni alia molestia beate vivat.

105 Iustissimus et potentissimus retribuat amanti se perseveranter.

106 Ad id ad quod. Cf. Id ad quod: L. 15. 
car y gozar del bien, el no aceptar este bien, significa una indigencia que es imposible llenar, porque va en contra la razón misma de la creación.

Así prueba Anselmo la inmortalidad (cc. 72-73) y recuerda (c. 74) que el Creador no nos priva de este bien hacia el cual fue hecha el alma (ad quod: 74; 83, 6), y hacia este (ad idem: L. 7) debe esforzarse con todo el corazón, toda el alma y toda la mente (L. 7-8). Anselmo recuerda el mandamiento del amor (Mt 22, 37), es importante señalarlo ${ }^{107}$.

Hasta ahora, Anselmo ha presentado la finalidad del ser humano con la preposición 'ad'. El c. 76 introduce la fe: "no se puede amar o esperar lo que no se cree"108 $(76 ; 83,16)$. Es importante entender las expresiones usadas: "Es bueno para la misma alma humana creer la Esencia eminente y las cosas sin las cuales ella no puede ser amada, para que, creyendo esta cosas, tienda en ella (in illam)" ${ }^{109}$ (L. 16-18). Anselmo cambia su vocabulario. Habla de creer en Dios (la fe tiene contenido) y de tender hacia él. Para eso, deja el ' $a d$ ' que indica la dirección, la finalidad y emplea el 'in' con acusativo para insistir no solo en la dirección sino el deseo de llegar hasta lo deseado, de adentrarse, de perderse en lo deseado. Ahora, Anselmo va a dejar el 'ad illam'y preferir el 'in illam' (p. 83, 26.27; $84,2)$. El tender en ella es creer en ella (p. 83, 22).

El c. 77 recuerda que la Esencia eminente es el Padre, Hijo y Espíritu. Esa es la Esencia eminente en la cual (in quam: 77; 84, 9) todo hombre debe creer porque es el único fin para nuestro pensamiento y nuestros actos. "Así como nadie puede tender en ella (in illam) si no la cree, también nadie aprovecha creerla si no tiende en ella (in illam)" 110 (L. 11.13).

Así llegamos a la fe viva y la fe muerta (c. 78). La carta de Santiago $(\mathrm{St})$ insiste en acercar la fe y las obras: la fe sin las obras está muerta ${ }^{111}$. La fe tiene que mostrar su realidad (su vivencia) a través de obras. El

107 Mismo razonamiento en PR 25; 120, 18.

108 Amare autem aut sperare non potest, quod non credit.

109 Expedit itaque eidem humanae animae summam essentiam et ea sine quibus illa amari non potest creder, ut illa credendo tendat in illam.

110 Sicut in illam tendere nisi credat illam nullus potest, ita illam credere nisi tendat in illam nulli prodest.

111 St 2, 17: Sic et fides, si non habeat opera, mortua est in semetipsa. 2, 20: fides sine operibus mortua est. 2, 26; sicut enim corpus sine spiritu mortuus est, ita est fides sine operibus mortua est. Podemos unir con Gal 5, 6: fides quae per charitatem operatur. 
ejemplo que toma Santiago del cuerpo sin espíritu (St 2, 26) representa las ideas de Anselmo: el cuerpo necesita el espíritu, el soplo de vida; así fue creado (Gn 2, 7); sin este soplo, no existe (Sal 104, 29). Así la fe necesita el soplo del amor de predilección ${ }^{112}(78 ; 84,17)$. La fe unida al amor nunca será ociosa porque "quien ama a la Justicia eminente no despreciará nada justo ni aceptará nada injusto"113 (L. 21-22).

Como el ciego es el que no ve cuando debe ver, así la fe es muerta porque no tiene dilección cuando debe tenerla siempre $(78 ; 85,5)$. El ocio es el desprecio. Así Anselmo puede definir la fe viva como "creer en eso en que se debe creer, mientras la fe muerta es creer solamente eso que se debe creer" ${ }^{114}$ (L. 8-9). La fe se muestra en el amor, necesita del amor para realizar sus obras. Para eso, la fe necesita adentrarse (in id in quod) en lo que debe creer, es decir, en la Naturaleza eminente. La fe muerta cree algo; es solamente racional o racionalista. La fe viva vive plenamente en el Dios Trinidad (cc. 79-80) para gozar de Él (c.1). La fe es la relación perfecta porque plena. Y así volvemos al inicio del Monologion.

\section{CONCLUSIÓN}

La tercera parte ya era una conclusión. Solamente podemos ahora recoger algunas ideas. La relación de la creatura con su Creador se refleja en el deseo de gozar del Bien infinito; es misterio y es esfuerzo. Para Anselmo, eso es el drama y este drama está presenta en todas sus obras: El Monologion lo marca de manera racional (sola ratione); el Proslogion a nivel escatológico; algunos libros resaltan la libertad y su la relación con lo infinito (De Veritate, De Libertate Arbitrii); otras la obra de Cristo (Cur Deus Homo) frente al pecado (De casu Diaboli).

El hombre moderno puede seguir la reflexión de Anselmo: le ayudará a profundizar el sentido entre la naturaleza y el Creador, o entre la naturaleza y el científico. Quizás el científico encontrará un tema que Anselmo no desarrolla: el tiempo o la historia. Desde los descubrimientos de la relatividad de Einstein, con los avances de la astronomía, los

112 En el vocabulario de Anselmo, hay que diferenciar amor y dilectio. Por eso, la traducción de amor de predilección. Cf. CORBIN I, 199, nota a.

113 Quod summam iustitiam diligit, nihil iustum contemnere, nihil valet iniustum admittere.

114 Viva fides credere in id in quod credi debet, mortua vero fides credere tantum id quod credi debet. 
científicos modernos están aprendiendo a considerar el factor tiempo. Para disculpar a Anselmo, podemos decir que él habla a sus hermanos monjes, hombres de su tiempo y que sus ideas permanecen hoy. Además si toda filosofía quiere ser atemporal, Anselmo no se priva de proyectar todos sus deseos en la escatología.

Los teólogos, probablemente, echarán de menos los temas cristológicos, en cuanto a la salvación. En el Monologion están (casi) ausentes. Por eso, Anselmo seguirá escribiendo. Tenemos el Cur Deus Homo que presenta su cristología y el De Casu Diaboli que profundiza el sentido del pecado 'puro' en el diablo.

Los escritos de nuestros antepasados tienen mucho valor porque reflejan el ser humano de su época en su universalidad. Anselmo puede ser hombre del siglo XI, puede ser agustiniano o platónico, sigue siendo un referente en tres temas: el sentido de la razón, es decir, cómo aceptar que el ser humano usando su sola razón pueda alcanzar (explicar en su profundidad) a otro ser, creado o increado; el argumento (mal) llamado ontológico, que prefiero llamar relacional o escatológico, es decir, la relación entre el ser creado y el ser infinito; la satisfacción vicaria o la relación en Cristo de lo finito e infinito porque es representante de los hombres ante el Dios ofendido por el pecado.

En otras palabras, el pensador (científico, filósofo, teólogo) tiene siempre delante el problema de la transcendencia que se une en él y en su ciencia, con la inmanencia. El drama perdura. 
